\title{
AN UNUSUAL PENETRATING FOREIGN BODY IN THE NECK
}

Cherian T A ${ }^{1}$, Pujari $K^{2}$, Joshi $B^{3}$,

\section{ABSTRACT}

A case of a penetrating injury of the neck sustained due to a flying fragment of metal is presented. The nature of the Injury and its management are discussed.

\section{Key Words: Neck Injury, Penetrating, Vascular Injury, Foreign Body.}

\section{REPORT}

A 22 year old patient presented to the Emergency Ward of the Western Regional Hospital, Pokhara with a history of having sustained an injury to the neck a few hours ago, stating that a piece of rock entered his neck when someone was chipping a rock with a crowbar- Following the trauma he had profuse bleeding from the neck, which was staunched by pressure.

On examination, he was alert and conscious with a pulse rate of 98/min; BP of 100/70mm Hg-There was a $1 \mathrm{~cm}$-long laceration $2 \mathrm{cms}$ lateral to the thyroid notch on the left side of the neck from which little blood was trickling. There was fullness of the neck on the left side and carotid pulsation was palpable. Blood was cross-matched, X-rays were taken to locate the foreign body, and the patient taken to the Operation theatre for a Neck exploration under General anaesthesia.

Fig. 1, X-Ray neck AP, soft tissue view; showing a densely radio-opaque shadow anterior to the $4^{\text {th }}$ and $5^{\text {th }}$ cervical vertebrae.

1. Associate Professor, ENT Department, Manipal College of Medical Sciences, Pokhara

2. Lecturer, ENT Department, Manipal College of Medical Sciences, Pokhara

3. Consultant Surgeon, Western Regional Hospital, Pokhara

Address for correspondence : $\quad$ Dr. Tambi Abraham Cherian, DLO, MS, DNB, ENT Department Manipal College of Medical Sciences, Pokhara 


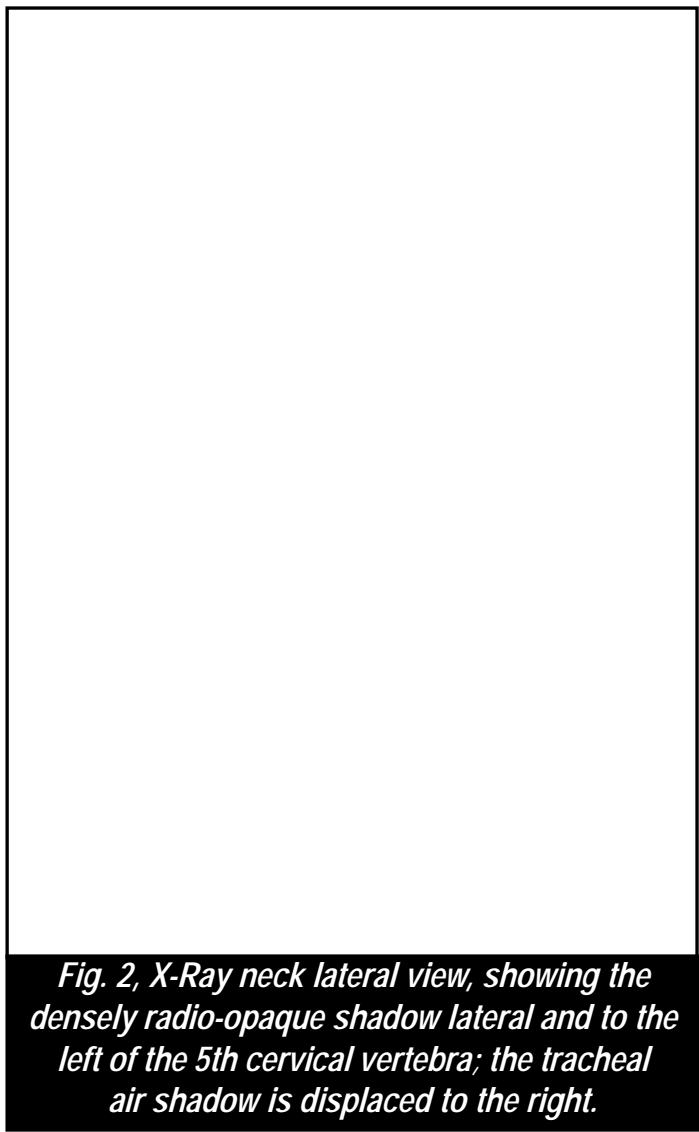

X-Ray neck soft tissue (lateral and AP views) showed a small densely radio opaque foreign body in the neck on the left side at the level of the 4th and 5th cervical vertebrae, the larynx and trachea were grossly deviated to the right.

The patient was fully conscious and insisted on walking into the Operation theatre, but as soon as he was on the table he started to bleed profusely from the neck wound. A rapid sequence intubation was done and the bleeding controlled by external pressure, while the neck was prepared and draped. With the application of pressure on the neck superiorly the neck was opened inferiorly with a vertical incision along the anterior border of the Stemocleidomastoid muscle. Suspecting a major vessel injury in the neck due to the torrential bleeding from the wound, the Carotid sheath was opened and the Carotid Artery controlled with vascular tapes. This maneuver did not lessen the hemorrhage and the neck was explored by further extending the incision superiorly. After removing large clots in the neck, bleeding vessels i.e. branches of the superior laryngeal artery and vein were ligated. The foreign body - a small fragment of metal $1.25 \mathrm{cms}$. in size was located in the Carotid sheath, between the Carotid at the bifurcation, and the Internal Jugular Vein. To remove the metal fragment the Internal Jugular Vein was ligated and divided, the Carotid Artery was found to be intact. The metal piece had punctured the neck, and turned laterally after striking the Thyroid cartilage to rest on the Carotid Artery after damaging the Laryngeal vascular pedicle. The neck was closed in layers and the patient made an unremarkable recovery.

\section{DISCUSSION}

Penetrating injuries of the neck are seen following assault with knives or bullet injuries. ${ }^{1}$ Accidental falls leading to impalement is another source of trauma to the neck. ${ }^{2}$ In this case the injury was due to a flying fragment of metal from a crowbar, which broke off on striking a rock. A similar case has been reported due to a splinter of metal from an axe while chopping wood. ${ }^{3}$ And another due to flying metal while cutting metal. ${ }^{4}$

Investigations of patients with penetrating neck wounds include X-rays, Barium swallow, endoscopy, arteriography and CT scans. Arteriography is not universally available but Color Dopplers are new more frequently accessible and can be used to assess vascular injuries in the neck. ${ }^{5,6}$

There is a difference of opinion regarding neck explorations in patients with penetrating neck wounds without obvious vascular or visceral injury. With proponents for mandatory neck exploration of wounds deep to the platysma, ${ }^{7,8,9}$ and those who wishing to avoid unnecessary neck explorations advocate a more conservative policy of observation and extensive investigation. ${ }^{10,11,12,13}$ In the scenario of a Regional Hospital with limited investigative and human recourses it would seem reasonable to advise neck exploration when faced with a visceral 
Fig. 3, Photograph of the foreign body, a fragment of metal measuring $1.25 \mathrm{cms}$ in size.

injury, emphysema in the neck spaces, hypovolaemic shock, active bleeding from the wound and a large or expanding hematoma, especially with absent Carotid artery pulsations.

As retained foreign bodies can produce retropharyneeal abscess as a late complication, ${ }^{14}$ it should be removed surgically, electively if not as an emergency procedure.

In situations of neck injury due to foreign bodies causing vascular injury, neck exploration with initial access to the Carotid sheath before attempting to search and remove the foreign body is safer and expedient.

Acknowledgements: We would like to thank the Medical Superintendent of the Western Regional Hospital Pokhara, for allowing us to publish this case report.

\section{REFERENCES}

1. "Penetrating neck wounds. Mandatory versus selective exploration". Ayuyao AM, Kaledzi YLParsa MFL Freeman H Ann Surg 1985 Nov; 202 (5) :563-7.

2 "Oropharyngeal foreign body" Mishra A, Shukia GK, Bhatia Naresh J Laryngol Otol. June 2000 vol 114 pp. 469-470.

3. "Throat pain after chopping wood. Penetrating trauma of the soft tissues of the neck caused by a metal splinter". Issing PR, Stover T HNO 1999 Dee; 47 (12) ; 1072-3.

4. "Unusual Impacted Flying Foreign Body in Thyroid Lobe" A. Chakraborty IJO-HNS Aug. 1999 pp 68-70.

5. "Evaluation of penetrating injuries of the neck: prospective study of 223 patients." Demetriades D, Theodorou D, Comwell E, Beme TV, Asensio J, Belzberg $\mathrm{H}$, Velmahos $\mathrm{G}$, Weaver $\mathrm{F}$, Yell in A World J Surg 1997 Jan; 21 (1) :41-7.

6 "Color Doppler sonography in penetrating injuries of the neck." Montalvo BM, LeBlang SD, Nunez DB Jr, Ginzburg E, Klose KJ, Becerra JL, Kochan JP AJNR Am J Neuroradiol 1996 May; 17 (5) : 943-51.

7. "Penetrating neck injuries". Siegrist B, Steeb G South Med J 2000 Jun; 93 (6) :567-70.

8. "The management of penetrating injuries of the anterior triangle of the neck". Walsh MS Injury 1994 Aug; 25 (6) : 393-5.

9. "Penetrating trauma of the neck" Saletta JD, Lowe RJ, Lim LT, Thoraton J, Delk S, Moss GS J Trauma $1976 \mathrm{Jul} ; 16$ (7) : 579-87.

10. "Non-therapeutic operations for penetrating trauma: early morbidity and mortality". Demetriades D, Vandenbossche P, Ritz M, Goodmann D, Kowalszik J Br J Surg 1993 Jul; 80 (7) : 860-1.

11. "Management of penetrating wounds of the neck". Luntz M, Nusem S, Kronenberg J Eur Arch Otorhinolaryngol 1993; 250 (7) : 369-74.

12. "Selective surgical management in penetrating neck inJuries." Velmahos GC, Souter I, Degiannis E, Mokoena T, Saadia R CanJ Surg 1994 Dec J7 (6) i 487-91.

13. "Evaluation and management of penetrating wounds of the neck; the role of emergency angiography" ODonnell VA, Atik M, Pick RA Am J Surg 1979 Aug; 138 (2) : 309-13.

14. "Retropharyngeal abscess complicating a neck wound (a case report) 'Yickles JM Jlarvngol Otol 1988 Jun; 102 (6) : 552-3.

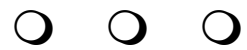

